\title{
PRAKIRAAN KEBUTUHAN ENERGI LISTRIK KABUPATEN BERAU
}

\author{
Fitriani $^{1}$, Abdul Aziz Ansahri ${ }^{2}$ \\ ${ }^{1}$ Jurusan Teknik Elektro, Universitas Borneo Tarakan, Kota Tarakan, Kalimantan Utara, Indonesia \\ ${ }^{2}$ PT. Berkat Jaya Sukses, Kab. Berau, Kalimantan Timur, Indonesia \\ email: ${ }^{1}$ fitrianiubt22@gmail.com, ${ }^{2}$ abdulazisansahriegmail.com
}

\begin{abstract}
Forecast or (forecast) is basically conjecture or prediction regarding the occurrence of an event or events in the future. Forecasts can be qualitative (not shaped figure) and quantitative (form number). Qualitative Forecast difficult to obtain a good result because the variables are very relative. Quantitative forecasts divided into two: the single forecasts (point forecast) and the forecast interval (interval forecast). In this research, the author forecast the number of customers and the need for electrical energy in Berau Regency in East Kalimantan Province. By using DKL 3.01 to forecast and project electrical energy needs in Berau Regency. The result of this final project is the estimated calculation of customer number and electricity requirement of Berau Regency from 2018 until 2027. The average increase of customer growth amount is $4.77 \%$. As well as an increase in electrical energy demand by $11.22 \%$, and electrical power $5.52 \%$.
\end{abstract}

Keywords-Forecast, Berau Regency, DKL 3:01

Intisari-Prakiraan atau (forecast) pada dasarnya adalah dugaan atau prediksi tentang terjadinya suatu peristiwa atau kejadian di masa depan. Prakiraan bisa kualitatif (gambar tidak berbentuk) dan kuantitatif (jumlah bentuk). Kualitatif Prakiraan sulit untuk mendapatkan hasil yang baik karena variabel yang sangat relatif. perkiraan kuantitatif dibagi menjadi dua: perkiraan tunggal (perkiraan titik) dan interval perkiraan (selang perkiraan). Dalam Penelitian ini penulis memperkirakan jumlah pelanggan dan kebutuhan energi listrik di Kabupaten Berau di Provinsi Kalimantan Timur. Dengan menggunakan DKL 3.01 untuk meramalkan dan memproyeksikan kebutuhan energi listrik di Kabupaten Berau. Hasil dari penelitian ini adalah estimasi perhitungan jumlah pelanggan dan kebutuhan listrik Kabupaten Berau dari tahun 2018 sampai 2027. Kenaikan rata-rata jumlah pertumbuhan pelanggan adalah $4,77 \%$. Serta kenaikan kebutuhan energi listrik sebesar $11,22 \%$, dan tenaga listrik $5,52 \%$.

Kata Kunci: Prakiraan, Kabupaten Berau, DKL 3.01

\section{PENDAhuluan}

Ketergantungan dalam pemakaian tenaga atau daya listrik pada saat ini sangat tinggi tidak hanya untuk kebutuhan penerangan, tetapi juga untuk mendukung kegiatan perekonomian. Kecenderungan pada saat ini, peningkatan kebutuhan energi listrik tidak seiring dengan peningkatan penyediaan energi listrik, dimana kapasitas daya terpasang masih tetap, sementara kebutuhan masyarakat terus meningkat seiring dengan meningkatnya jumlah penduduk dan kegiatan pendukungnya. Akibat yang ditimbulkan adalah seringnya terjadi pemadaman aliran listrik, khususnya pada jam-jam tertentu (beban puncak). Kondisi ini mengharuskan dilakukannya pengembangan penyediaan tenaga listrik pada tahuntahun mendatang yang meliputi pengembangan pembangkit, sistem kontrol dan proteksi, serta sistem transmisi dan distribusi ke konsumen.

Kabupaten Berau khususnya di Tanjung Redeb merupakan salah satu daerah yang perkembangannya cukup pesat dalam berbagai bidang terutama dalam bidang industri, perdagangan, perhotelan dan juga kebutuhan rumah tangga yang diiringi dengan pesatnya peningkatan pembangunan dibidang teknologi dan informasi, dan merupakan suatu kenyataan bahwa kebutuhan akan energi (khususnya energi listrik) serta ketersedian dan pendistribusian energi listrik menjadi bagian yang tak terpisahkan dari kebutuhan hidup masyarakat sehari-hari.

\section{LANDASAN TEORI}

A. Tipe Beban

Tenaga listrik yang didistribusikan ke pelanggan (konsumen) digunakan sebagai sumber daya untuk bermacam-macam peralatan yang membutuhkan tenaga listrik sebagai sumber energinya. Tipe-tipe beban konsumen pemakai pada umumnya dapat dikelompokkan dalam kategori berikut:
a) Rumah Tangga
b) Bisnis.
c) Umum/ publik.
d) Industri.

\section{B. Prakiraan}

Prakiraan atau forecast pada dasarnya merupakan dugaan atau peramalan mengenai terjadinya suatu kejadian atau peristiwa di waktu yang akan datang.

\section{Metode Peramalan}

Secara umum terdapat lima kelompok besar metoda peramalan adalah sebagai berikut:

a) Metode Sampling Statistik

b) Metode Ekstrapolasi

c) Metode Perbandingan

d) Metode Sektoral

e) Metode Gabungan 
D. Faktor yang Mempengaruhi Prakiraan

Dalam membuat prakiraan kebutuhan tenaga listrik kita tidak dapat mengabaikan faktor-faktor di luar bidang kelistrikan yang berpengaruh seperti, perkembangan penduduk, pertumbuhan ekonomi, rencana pengembangan daerah, pertumbuhan industri dan juga beberapa kebijaksanaan pemerintah baik dari pusat maupun daerah.

\section{E. Metode DKL}

Pemodelan prakiraan kebutuhan tenaga listrik menggunakan program DKL merupakan penggabungan dari beberapa metode yaitu penggabungan metode ekstrapolasi, metode sektoral dan metode gabungan. Masukan yang diperlukan dalam program ini adalah datadata sosio demografi, data pengusahaan dari penyelenggara kelistrikan, serta data ekonomi.

\section{Parameter-Parameter Yang Diprakirakan}

Dalam penyusunan prakiraan kebutuhan energi listrik ini, parameter-parameter yang diprakirakan adalah sebagai berikut:

a) Prakiraan jumlah penduduk dan jumlah rumah tangga,

b) Prakiraan jumlah pelanggan rumah tangga, komersial, publik, dan industri,

c) Prakiraan daya tersambung untuk pelanggan rumah tangga, komersial, publik, dan industri,

d) Prakiraan konsumsi energi untuk pelanggan rumah tangga, komersial, publik, dan industri.

\section{Elastisitas Energi}

Elastisitas Energi merupakan hasil dari perbandingan pertumbuhan konsumsi energi listrik dengan pertumbuhan ekonomi. Secara matematik dapat ditulis dengan persamaan.

$$
\begin{aligned}
& e E X=\frac{P E L}{G T} \\
& \text { dengan: } \\
& e E X=\text { Elastisitas energi } \\
& \text { PEL = Jumlah pertumbuhan persektor } \\
& G T=\text { Petumbuhan PDRB total }
\end{aligned}
$$

\section{Tahapan Prakiraan}

Tahapan prakiraan kebutuhan energi listrik dengan metode DKL 3.01 adalah sebagai berikut:

\section{Sektor Rumah Tangga}

- Jumlah Penduduk

Secara matematis untuk menentukan prakiraan jumlah penduduk total adalah sebagai berikut:

$P_{t}=P_{t-1} \times(1+r)^{t}$

dengan:

$\mathrm{P}_{\mathrm{t}} \quad=$ Jumlah penduduk tahun ke $\mathrm{t}$

$\mathrm{P}_{\mathrm{t}-1}=$ Jumlah penduduk tahun ke $\mathrm{t}-1$

$\mathrm{r} \quad=$ Pertumbuhan penduduk $(\%)$

$\mathrm{t} \quad=$ Waktu dalam tahun
- Jumlah Rumah Tangga

Secara matematis untuk menentukan prakiraan jumlah rumah tangga adalah sebagai berikut:

$H_{t}=\frac{P_{t}}{Q_{t}}$

dengan:

$\mathrm{H}_{\mathrm{t}}=$ Jumlah rumah tangga pada tahun $\mathrm{t}$

$\mathrm{P}_{\mathrm{t}}=$ Jumlah penduduk pada tahun $\mathrm{t}$

$\mathrm{Q}_{\mathrm{t}}=$ Jumlah penghuni per rumah tangga pada tahun ke $\mathrm{t}$

- Pelanggan Rumah Tangga

Dari rasio elektrifikasi yang telah diperkirakan/ ditargetkan serta dari jumlah rumah tangga yang telah dibuat prakirakan, jumlah pelanggan rumah tangga dapat ditentukan. Secara matematis untuk menentukan prakiraan jumlah pelanggan rumah tangga adalah sebagai berikut:

$$
\text { Pel. } R_{t}=H_{t} \cdot R E_{t}
$$

dengan:

Pel. $R_{t}=$ Pelanggan rumah tangga total pada tahun $\mathrm{t}$

$H_{\mathrm{t}} \quad=$ Jumlah rumah tangga pada tahun $\mathrm{t}$

$R E_{t} \quad=$ Rasio elektrifikasi pada tahun $\mathrm{t}$

- Daya Tersambung Rumah Tangga

Secara matematis dinyatakan:

$V A R_{t}=V A R_{t-1}+\left(P P e l . R_{t} \times V R\right)$

dengan:

VAR $_{\mathrm{t}}=$ Daya tersambung rumah tangga tahun ke $\mathrm{t}$

VAR $_{\mathrm{t}-1}=$ Daya tersambung rumah tangga tahun sebelumnya

VR = Daya tersambung per pelanggan rumah tangga

PPel. $\mathrm{R}_{\mathrm{t}}=$ Penambahan pelanggan rumah tangga tahun ke $\mathrm{t}$

- Konsumsi Energi Rumah Tangga

Secara matematis prakiraan energi rumah tangga dinyatakan sebagai berikut:

$E R_{\mathrm{t}}=E R_{\mathrm{t}-1} \times(1+r)^{\mathrm{t}}$

dengan:

$\mathrm{ER}_{\mathrm{t}}=$ Konsumsi energi rumah tangga tahun ke $\mathrm{t}$

$\mathrm{ER}_{\mathrm{t}-1}=$ Konsumsi energi rumah tangga tahun ke $\mathrm{t}-1$

$\mathrm{r} \quad=$ Laju pertumbuhan konsumsi energi rumah tangga

$\mathrm{t} \quad=$ Tahun yang dilewati

2. Sektor Bisnis

- Pelanggan Bisnis

Secara matematis untuk menentukan prakiraan jumlah pelanggan bisnis adalah sebagai berikut:

$P e l_{x} B_{t}=P_{e l} B_{t-1} \times\left(1+\left(\frac{F_{b r} \times P P R_{r}}{100}\right)\right) \ldots$

dengan:

Pel. $\mathrm{B}_{\mathrm{t}}=$ Pelanggan bisnis pada tahun ke $\mathrm{t}$

$\mathrm{F}_{\mathrm{bt}} \quad=$ Faktor pelanggan

$\mathrm{PPR}_{\mathrm{t}}=$ Pertumbuhan pelanggan rumah tangga pada tahun $\mathrm{t}$

Pel. $\mathrm{B}_{\mathrm{t}-1}=$ Pelanggan bisnis pada tahun $\mathrm{t}-1$ 
Faktor pelanggan bisnis merupakan rasio pertumbuhan pelanggan bisnis terhadap pertumbuhan pelanggan rumah tangga yang diperoleh dari hasil analisa data statistik.

- Daya Tersambung Bisnis

Prakiraan daya tersambung sektor bisnis ditentukan dengan rumus sebagai berikut:

$V A B_{t}=V A B_{t-1}+\left(P P e l . B_{t} \times V B\right)$

dengan:

$\mathrm{VAB}_{\mathrm{t}}=$ Daya tersambung bisnis pada tahun ke $\mathrm{t}$

$\mathrm{VAB}_{\mathrm{t}-1}=$ Daya tersambung bisnis pada tahun ke $\mathrm{t}-1$

PPel. $B_{t}=$ Penambahan pelanggan bisnis tahun ke $\mathrm{t}$

$\mathrm{VB} \quad=$ Daya tersambung rata-rata per pelanggan

- Konsumsi Energi Bisnis

Prakiraan konsumsi energi sektor bisnis ditetukan dengan rumus sebagai berikut:

$E B_{t}=E B_{t-1} \times\left(1+\left(\varepsilon E B \times \frac{G B_{t}}{100}\right)\right)$

dengan:

$\mathrm{EB}_{\mathrm{t}}=$ Konsumsi energi bisnis pada tahun $\mathrm{t}$.

$\mathrm{EB}_{\mathrm{t}-1}=$ Konsumsi energi bisnis pada tahun $\mathrm{t}-1$

eEB = Elastisitas energi bisnis

GB = Pertumbuhan PDRB sektor bisnis

3. Sektor Publik

- Pelanggan Publik

Pertumbuhan jumlah pelanggan publik diasumsikan dipengaruhi oleh jumlah pelanggan rumah tangga yang ditunjukkan dengan elastisitas pelanggan publik atau rasio pertumbuhan pelanggan publik terhadap pertumbuhan pelanggan rumah tangga. Prakiraan pelanggan publik ditentukan dengan rumus sebagai berikut:

Pel. $P_{\mathrm{t}}=$ Pel. $P_{\mathrm{t}-1} \times\left(1+\left(\frac{F_{\mathrm{ut}} \times P P R_{\mathrm{t}}}{100}\right)\right)$

dengan:

Pel. $\mathrm{P}_{\mathrm{t}}=$ Pelanggan publik pada tahun $\mathrm{t}$.

Pel. $P_{t-1}=$ Pelanggan publik pada tahun $\mathrm{t}-1$

$\mathrm{PPR}_{\mathrm{t}}=$ Pertumbuhan pelanggan rumah tangga pada tahun $\mathrm{t}$

$\mathrm{Fp}_{\mathrm{t}} \quad=$ Faktor pelanggan

Faktor pelanggan publik merupakan rasio pertumbuhan pelanggan publik terhadap pertumbuhan pelanggan rumah tangga yang diperoleh dari hasil analisa data statistik.

- Daya Tersambung Publik

Prakiraan daya tersambung sektor publik ditentukan dengan rumus sebagai berikut :

$V_{A} P_{\mathrm{t}}=$ VAP $_{\mathrm{t}-1}+\left(\right.$ PPel. $\left.P_{\mathrm{t}} \times P\right)$

dengan:

$\mathrm{VAP}_{\mathrm{t}}=$ Daya tersambung publik pada tahun ke $\mathrm{t}$.

$\mathrm{VAP}_{\mathrm{t}-1}=$ Daya tesambung publik pada tahun ke $\mathrm{t}-1$

PPel. $\mathrm{P}_{\mathrm{t}}=$ Penambahan pelanggan publik pada tahun ke $\mathrm{t}$

$\mathrm{VP}=$ Daya tersambung rata-rata per pelanggan

- Konsumsi Energi Publik
Prakiraan konsumsi energi sektor publik ditetukan dengan rumus sebagai berikut:

$E P_{t}=E P_{t-1} \times\left(1+\left(\varepsilon E P \times \frac{G P_{t}}{100}\right)\right)$

dengan:

$\mathrm{EP}_{\mathrm{t}} \quad=$ Konsumsi energi publik pada tahun ke $\mathrm{t}$.

$\mathrm{EP}_{\mathrm{t}-1}=$ Konsumsi energi publik pada tahun $\mathrm{t}-1$

$\mathrm{eEP}=$ Elastisitas energi publik

$\mathrm{GP}=$ Pertumbuhan PDRB sektor publik

4. Sektor Industri

- Pelanggan Industri

Prakiraan pelanggan untuk sektor industri ditentukan dengan rumus sebagai berikut :

Pel. $I_{t}=$ Pel. $I_{t-1} \times\left(1\left(\frac{F_{s t} \times P P R_{t}}{100}\right)\right)$

dengan:

Pel. $\mathrm{I}_{\mathrm{t}}=$ Pelanggan industri pada tahun $\mathrm{t}$.

Pel.I $\mathrm{I}_{\mathrm{t}-1}=$ Pelanggan industri pada tahun $\mathrm{t}-1$

$\mathrm{PPR}_{\mathrm{t}}=$ Pertumbuhan pelanggan rumah tangga pada tahun $\mathrm{t}$

$\mathrm{FI}_{\mathrm{t}} \quad=$ Faktor pelanggan industri

- Daya Tersambung Industri

Prakiraan daya tersambung sektor industri ditentukan dengan rumus sebagai berikut:

$V A I_{t}=V A I_{t-1}+\left(\right.$ PPel. $\left.I_{t} \times V I\right)$

dengan:

$\mathrm{VAI}_{\mathrm{t}}=$ Daya tersambung industri pada tahun ke $\mathrm{t}$.

$\mathrm{VAI}_{\mathrm{t}-1}=$ Daya tesambung industri pada tahun ke $\mathrm{t}-1$

PPel. $\mathrm{I}_{\mathrm{t}}=$ Penambahan pelanggan industri pada tahun ke $\mathrm{t}$

$\mathrm{VI}=$ Daya tersambung rata-rata per pelanggan industri

- Konsumsi Energi Industri

Prakiraan konsumsi energi sektor industri diperoleh dari penjumlahan energi terjual sektor industri. Prakiraan tersebut ditentukan dengan rumus sebagai berikut:

$E I_{t}=E I_{t-1} \times\left(1+\left(e E I \times \frac{G I}{100}\right)\right)$

dengan:

$\mathrm{EI}_{\mathrm{t}}=$ Konsumsi energi industri pada tahun ke $\mathrm{t}$.

$\mathrm{EI}_{\mathrm{t}-1} \quad=$ Konsumsi energi industri pada tahun $\mathrm{t}-1$

Eei $=$ Elastisitas energi industri

GI = Pertumbuhan PDRB sektor industri

\section{METODE PENELITIAN}

Penelitian ini dilakukan dengan tahapan - tahapan:

a) Studi kepustakaan.

b) Evaluasi dan validasi data.

c) Menggunakan perhitungan dari rumus-rumus baku.

d) Menganalisa dengan metode-metode pemikiran ilmiah.

e) Menganalisa data teknik data BPS (Badan Pusat Statistik) Kabupaten Berau.

Kerangka penelitian ini dapat dilihat pada Gambar 1. 


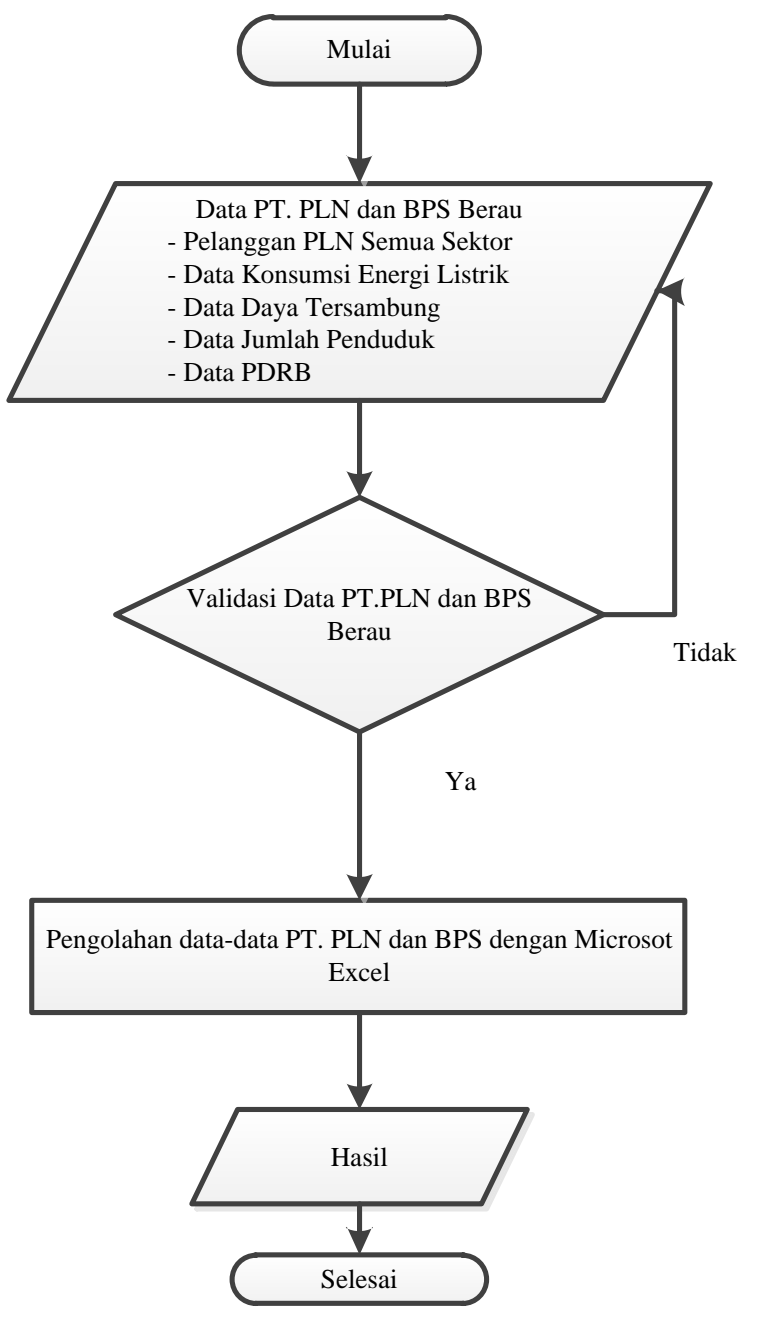

Gambar 1. Flowchart Kerangka Penelitian

\section{HASIL DAN PEMBAHASAN}

A. Prakiraan jumlah pelanggan Kabupaten Berau

Berdasarkan hasil prakiraan jumlah pelanggan Kabupaten Berau rata-rata total pertumbuhan pelanggan dari tahun 2018-2027 sebesar $12,36 \%$ per tahun dengan rata-rata pertumbuhan masing-masing sektor yaitu, Rumah Tangga sebesar 14,99\%, Industri sebesar 7,72\%, Bisnis sebesar 11,64\%, dan Publik sebesar 15,07\%.
Tabel I.

Prakiraan Jumlah Pelanggan Kabupaten Berau

\begin{tabular}{|c|c|c|}
\hline \multicolumn{3}{|c|}{ Prakiraan Jumlah Penduduk (Pt) } \\
\hline No & Tahun & Jiwa \\
\hline 1 & 2018 & 224.812 \\
\hline 2 & 2019 & 231.704 \\
\hline 3 & 2020 & 238.808 \\
\hline 4 & 2021 & 246.130 \\
\hline 5 & 2022 & 253.677 \\
\hline 6 & 2023 & 261.454 \\
\hline 7 & 2024 & 269.471 \\
\hline 8 & 2025 & 277.733 \\
\hline 9 & 2026 & 286.248 \\
\hline 10 & 2027 & 295.024 \\
\hline
\end{tabular}

B. Prakiraan jumlah pelanggan Kabupaten Berau

Berdasarkan hasil prakiraan jumlah pelanggan Kabupaten Berau rata-rata total pertumbuhan pelanggan dari tahun 2018-2027 sebesar 12,36\% per tahun dengan rata-rata pertumbuhan masing-masing sektor yaitu, Rumah Tangga sebesar 14,99\%, Industri sebesar 7,72\%, Bisnis sebesar 11,64\%, dan Publik sebesar 15,07\%.

Tabel II.

Prakiraan Jumlah Pelanggan Kabupaten Berau

\begin{tabular}{|c|c|c|c|c|c|}
\hline \multicolumn{6}{|c|}{$\begin{array}{c}\text { Prakiraan Jumlah Pelanggan Energi Listrik Kabupaten } \\
\text { Berau }\end{array}$} \\
\hline No & Tahun & $\begin{array}{l}\text { Rumah } \\
\text { Tangga }\end{array}$ & Bisnis & Publik & Industri \\
\hline 1 & 2018 & 48.179 & 2.906 & 1.508 & 23 \\
\hline 2 & 2019 & 51.414 & 3.040 & 1.550 & 24 \\
\hline 3 & 2020 & 54.866 & 3.179 & 1.593 & 25 \\
\hline 4 & 2021 & 58.550 & 3.325 & 1.637 & 25 \\
\hline 5 & 2022 & 62.482 & 3.477 & 1.683 & 26 \\
\hline 6 & 2023 & 66.677 & 3.637 & 1.730 & 26 \\
\hline 7 & 2024 & 71.154 & 3.804 & 1.778 & 27 \\
\hline 8 & 2025 & 75.932 & 3.978 & 1.828 & 27 \\
\hline 9 & 2026 & 81.030 & 4.160 & 1.879 & 28 \\
\hline 10 & 2027 & 86.471 & 4.351 & 1.931 & 28 \\
\hline \multicolumn{2}{|c|}{ Rata-Rata } & 65.675 & 3.586 & 1.712 & 26 \\
\hline
\end{tabular}

C. Prakiraan Kebutuhan Energi Listrik Kabupaten Berau

Hasil prakiraan kebutuhan energi listrik Kabupaten Berau menunjukkan adanya peningkatan dari tahun 2018 dengan total kebutuhan 125.785.634 kWh menjadi 188.182.469 kWh pada tahun 2027. Dengan rata-rata pertumbuhan kebutuhan energi dari tahun 20182027adalah sektor rumah tangga $3,41 \%$, sektor industri $1,92 \%$, sektor bisnis $6,22 \%$, dan sektor publik $7,86 \%$. 
Tabel III.

Prakiraan Konsumsi Energi Listrik Kabupaten Berau

\begin{tabular}{|c|c|c|c|c|c|c|}
\hline \multicolumn{7}{|c|}{ Proyeksi Prakiraan Konsumsi Energi Listrik Pada Setlap Sektor di Kabupaten } \\
Berau
\end{tabular}

\section{KESIMPULAN}

Hasil yang didapatkan pada prakiraan jumlah pelanggan Kabupaten Berau rata-rata total pertumbuhan pelanggan dari tahun 2018-2027 sebesar $\mathbf{1 2 , 3 6 \%}$ pertahun dengan rata-rata ertumbuhan masing-masing sektor yaitu, Rumah Tangga sebesar 14,99\%, Bisnis sebesar 11,64\%, dan Publik sebesar 15,07\%, Industri sebesar $\mathbf{7 , 7 2 \%}$. Hasil prakiraan kebutuhan energi listrik Kabupaten Berau menunjukkan adanya peningkatan dari tahun 2018 dengan total kebutuhan 125.785 .634 kWh menjadi 188.182.469 $\mathbf{k W h}$ pada tahun 2027. Dengan ratarata pertumbuhan jumlah kebutuhan energi listrik jika di persentase sebesar $\mathbf{4 , 8 5 \%}$. Rata-rata pertumbuhan kebutuhan energi dari tahun 2018-2027untuk sektor rumah tangga $\mathbf{3 , 4 1 \%}$, sektor bisnis $\mathbf{6 , 2 2 \%}$, sektor publik $\mathbf{7 , 8 6 \%}$ dan sektor industri $\mathbf{1 , 9 2 \%}$. Hasil prakiraan daya tersambung Kabupaten Berau menunjukkan adanya peningkatan dari tahun 2018 dengan total kebutuhan 73.278 kVA menjadi 233.707 kVA pada tahun 2027. Dengan persentase rata-rata total pertumbuhan kebutuhan daya listrik sebesar $\mathbf{1 2 , 3 6 \%}$. Rata-rata daya listrik tersambung dari tahun 2018-2027adalah sektor rumah tangga 14,99\%, sektor bisnis $\mathbf{1 1 , 6 4 \%}$, sektor publik $\mathbf{1 5 , 0 7 \%}$ dan sektor industri $\mathbf{7 , 7 2 \%}$.

\section{REFERENSI}

[1] Pudjanarso, Astu. (2013). Mesin Konversi Energi, Edisi Ketiga. Yogyakarta: Andi

[2] Adinda, Ayu. (2013), Prakiraan Kebutuhan Beban Dan Energi Listrik Kebupaten Kendal, Universitas Diponegoro, Semarang.

[3] Axella, Oxa. (2012), “Aplikasi Model Sistem Dinamik untuk Menganalisis Permintaan dan Ketersediaan Listrik Sektor Industri", JURNAL TEKNIK ITS, Vol.1, hal 339 - 344.

[4] Badan Pusat Statistik. Kabupaten Berau Dalam Angka 2008, Tanjung Redeb, 2008.

[5] Badan Pusat Statistik. Kabupaten Berau Dalam Angka 2018, Tanjung Redeb, 2018.

[6] Binoto Maju, dan Yulianti Kristawan. (2015). Peramalan Energi Listrik Tersambung Pada Sistem
Ketenagalistrikan Untuk Jangka Panjang Di Solo Menggunakan Model Artificial Neural Network. 2.

[7] Fitrionto Kurniawan. Prakiraan Kebutuhan Energi Listrik Tahun 2006-2015 Pada PT.PLN (Persero) Unit Pelayanan Jaringan (UPJ) Di Wilayah Kota Semarang Dengan Metode Gabungan. Skripsi, Konsentrasi Ketenagaan Jurusan Teknik Elektro Fakultas Teknik Universitas Diponegoro Semarang,2006.

[8] Potensi Ekonomi, Edisi Ketiga/Revisi. Jakarta: Universitas Indonesia.

[9] Nurhalim dkk. (2015). Analisis Prakiraan Kebutuhan Energi Listrik Tahun 2015-2-24 Wilayah PLN Kota Pekanbaru Dengan Metode Gabungan. 2 